\title{
Spontaneous abortions in hospital staff engaged in sterilising instruments with chemical agents
}

\author{
K HEMMINKI, P MUTANEN, I SALONIEMI, M-L NIEMI, H VAINIO
}

\begin{abstract}
Spontaneous abortions in hospital sterilising staff were analysed using data from a postal questionnaire and a hospital discharge register. The study included all the sterilising staff employed in Finnish hospitals in 1980; the controls were nursing auxiliaries. Data from the questionnaire showed that the frequency of spontaneous abortions was $11.3 \%$ for the sterilising staff and $10.6 \%$ for the nursing auxiliaries. When the staff were concerned in sterilising procedures during their pregnancy the frequency was $16.7 \%$ compared with $5.6 \%$ for the non-exposed pregnancies. Adjustment for age, parity, decade of pregnancy, smoking habits, and intake of coffee and alcohol did not affect the differences. The increased frequency of spontaneous abortion correlated with exposure to ethylene oxide but not with exposure to glutaraldehyde or to formaldehyde. Analysis of spontaneous abortions from the hospital discharge register confirmed the findings. Thus the results from the two independent analyses suggest that exposure to ethylene oxide in hospitals may carry a risk of spontaneous abortion among sterilising staff.
\end{abstract}

\section{Introduction}

When heat-sensitive material has to be sterilised chemical agents have to be used rather than sterilisation by hot-water vapour. More than 100000 people are estimated to be employed worldwide in the chemical sterilisation of medical instruments, pharmaceutical preparations, and food stuffs. ${ }^{1}$ The gases and liquids used-for example, ethylene oxide, formaldehyde, glutaraldehyde and $\beta$-propiolactone-react covalently with macromolecules and destroy all living organisms. ${ }^{2}$ The capacity of chemicals to form covalent bonds with macromolecules has recently been correlated with their carcinogenic potential, ${ }^{3}$ which gives rise to concern about the possible ill effects of chemical sterilising agents. Ethylene oxide, ${ }^{4}$ formaldehyde, ${ }^{5}$ and $\beta$-propiolactone ${ }^{6}$ have produced tumours in experimental animals, and some evidence of the carcinogenicity of ethylene oxide has been found in man. ${ }^{7}$ Experimental embryotoxicity has been reported for ethylene oxide, ${ }^{8}$ glutaraldehyde, ${ }^{8}$ and formaldehyde. ${ }^{9}$

In the present study we analysed the incidence of spontaneous abortion among hospital staff in Finland who used ethylene oxide, glutaraldehyde, and formaldehyde for the chemical sterilisation of instruments.

\section{Patients and methods}

QUESTIONNAIRES

Questionnaires were sent to the supervising nurses in all the general hospitals (about 80 ) in Finland to ascertain the quantities of chemical sterilising agents used and the names of the female staff using the particular agents. Six months later, when all the hospitals had responded, the supervising nurses were sent two further sets of questionnaires and prepaid return envelopes, together with detailed instructions on how to distribute them. One set of questionnaires, each labelled with the women's names, was given to the sterilising staff; the other was distributed to an equal number of controls after selection by the supervising nurses from nursing auxiliaries in the same hospital who had not been exposed to sterilising agents, anaesthetic gases, or $x$ rays. The questionnaire asked for the following details of the staff: their social security number, home address, husband's name, number of pregnancies and their outcome, occupation at the time of each pregnancy, employer, children's health, smoking habits, and intake of alcohol, tea, and coffee. The questionnaire did not inquire about chemical sterilising agents so as to avoid asymmetry between the two groups and to conceal the purpose of the study. Information about exposure to chemical sterilising agents was obtained from the supervising nurses. After one reminder $91.6 \%$ of the sterilising staff and $90.6 \%$ of the nursing auxiliaries who could be contacted replied.

The information in the questionnaires was coded for analysis of the pregnancies and exposures to specified agents at the beginning of the pregnancy. The pregnancies ending in an induced abortion were excluded because hospital records showed considerable underreporting of induced abortions.

\section{STATISTICAL ANALYSIS}

The results are given as crude rates or as adjusted rates controlled for age $(\leqslant 20 ; 21-34 ; \geqslant 35$ years, qualitative variable), parity $(0,1,2$, $>2$, continuous variable), decade of reported pregnancy (before 1961, 1961-70, 1971-80, qualitative variable), smoking habits $(0,1-10,>10$ cigarettes/day, qualitative variable), alcohol consumption (rarely, 2-3 times/month, one/week, daily, qualitative variable), and coffee drinking $(<5,5-6,>6$ cups/day, qualitative variable) using a linear logistic regression model. ${ }^{10} 11$

When analysed individually all these variables appeared to be associated with spontaneous abortions, although some associations were weak. The different exposure covariates were binary indicators of the exposure. When the model was fitted the estimated values of the parameters were adjusted for all the included variables. The binary logistic regression model gives a direct estimate of the odds ratio and an equation for the calculation of the adjusted rates. ${ }^{10}$ Significance was evaluated by the $\chi^{2}$ test for the crude rates and by testing of the regression coefficients for the adjusted rates. ${ }^{10}$

\footnotetext{
Institute of Occupational Health, Haartmaninkatu 1, SF-00290 Helsinki 29, Finland

K HEMMINKI, MD, scientist

$P$ MUTANEN, MS, scientist

I SALONIEMI, BS, scientist

M-L NIEMI, CAND POL SCI, scientist

$\mathrm{H}$ VAINIO, $\mathrm{MD}$, head of department
}

\section{HOSPITAL DISCHARGE DATA}

In addition to the data in the questionnaires details of the pregnancies and their outcome for the sterilising staff and the controls were obtained from a hospital discharge register, which covered all Finland between 1973 and 1979. A detailed description of the use of this source of data in studies of spontaneous abortions is found elsewhere. ${ }^{12-14}$ The pregnancies of the sterilising staff and of the controls were identified by the social security number. The data on patients treated for spontaneous abortion (diagnoses No 643 and 645, with no preceding abortion), induced abortion (diagnoses No 640-642), and on women giving birth (diagnoses No 650-662) were analysed according to the eighth revision of the International Classification of Diseases. The number of spontaneous abortions was related to the number of 
pregnancies (births + induced abortions + spontaneous abortions), referred to as the rate of spontaneous abortions; and to the number of births, referred to as the ratio of spontaneous abortions, in each group of women. ${ }^{12} 13$

\section{Results}

When the decade of the reported pregnancy was studied in relation to the frequency of spontaneous abortions to detect any differences in the recall or reporting of spontaneous abortions (figure) the frequency of spontaneous abortions was higher in the pregnancies in which the women were exposed to sterilising agents than in nonexposed women who became pregnant. A time-dependent increase in the frequency of reported spontaneous abortions was noted in all the groups analysed. This is explained to a small extent by the aging of the population, as a crude age group (20-34 years) was used. The main reason for the apparent increase was the fact that the reporting of spontaneous abortions was higher for the most recent decade. Thus it was important to control the data for the decade of the pregnancy reported. Other variables that were controlled in the analysis were age, parity, smoking habits, and alcohol and coffee consumption.

The crude rates of spontaneous abortions were $11.3 \%$ for the sterilising staff and $10.6 \%$ for the control group (table I). When the pregnancies of the sterilising staff were analysed according to employment at the time of conception the rates were $16.7 \%$ for the exposed and $6.0 \%$ for the non-exposed women. Even when the data were adjusted for maternal age, parity, decade of pregnancy, smoking

TABLE I-Spontaneous abortion rate among sterilising staff and nursing auxiliaries (controls)

\begin{tabular}{|c|c|c|c|}
\hline & \multirow{2}{*}{$\begin{array}{l}\text { Total No of } \\
\text { pregnancies }\end{array}$} & \multicolumn{2}{|c|}{ Spontaneous abortion rate } \\
\hline & & $\underset{(\%)}{\text { Crude }}$ & $\underset{(0)}{\text { Adjusted }}$ \\
\hline $\begin{array}{l}\text { Sterilising staff } \\
\text { Exposed during pregnancy } \\
\text { Exposure uncertain } \\
\text { Not exposed during pregnancy } \\
\text { Controls }\end{array}$ & $\begin{array}{r}1443 \\
545 \\
293 \\
605 \\
1179\end{array}$ & $\begin{array}{c}11 \cdot 3 \\
16 \cdot 7 \dagger \\
12 \cdot 3 \dagger \\
6 \cdot 0 \\
10 \cdot 6\end{array}$ & $\begin{array}{c}9 \cdot 7 \\
15 \cdot 1 \dagger \\
11 \cdot 3 \dagger \\
4 \cdot 6 \\
10 \cdot 5\end{array}$ \\
\hline
\end{tabular}

* Rates adjusted for age, parity, decade of reported pregnancy, coffee and alcohol consumption, and smoking habits.

$+\mathrm{p}<0.001$ (exposed $v$ non-exposed pregnancies) habits, and alcohol and coffee consumption the frequency of spontaneous abortions was still increased in the exposed pregnancies (table I).

The effects of the different sterilising agents on the frequency of spontaneous abortions were analysed (table II). Exposure to ethylene oxide during early pregnancy appeared to be correlated with an increase in the adjusted rate of spontaneous abortions from $7.8 \%$ to $16.1 \%(p<0.01)$. Exposure to glutaraldehyde increased only the crude but not the adjusted rate. Similar increases were seen when one

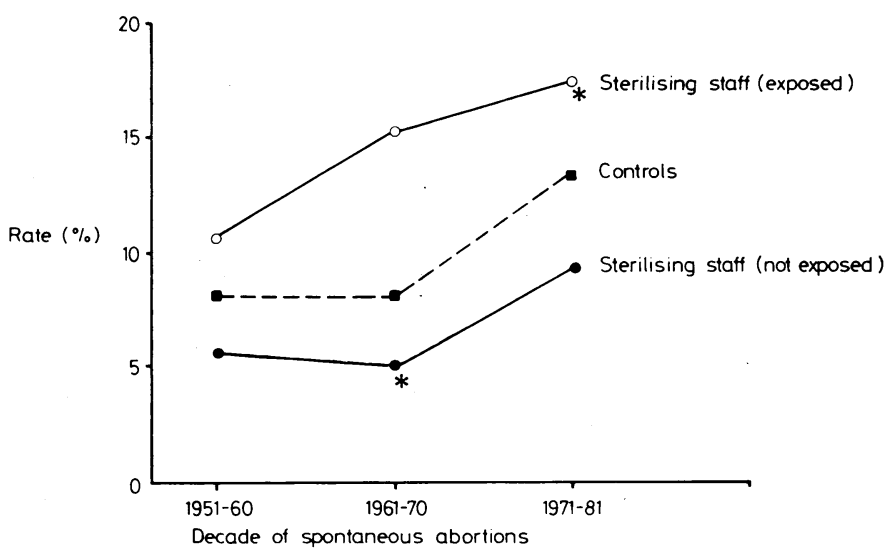

Parity-adjusted frequency of reported spontaneous abortions during three decades in three groups of women aged $20-34$ years. $\left({ }^{*} p<0.05\right.$ from the mean rate $(10.6 \%)$ for the controls.)

of the two agents was used in combination with others. By contrast, exposure to formaldehyde did not correlate with an increase in spontaneous abortions.

When data on the pregnancies of the sterilising staff and the controls obtained from the hospital discharge register were analysed the rate of spontaneous abortions was $14.2 \%$ for the exposed and $9.9 \%$ for the non-exposed staff (table III). The controls had a rate of $9 \cdot 2 \%$. Equally large differences occurred in the ratios. The differences were found in all age groups. Exposure to ethylene oxide accounted for most of the excess spontaneous abortions.

TABLE II-Effect of exposure to ethylene oxide, glutaraldehyde, and formaldehyde on the frequency of spontaneous abortions. (Rates adjusted for age, parity, decade of pregnancy, smoking habits, and alcohol and coffee consumption)

\begin{tabular}{|c|c|c|c|c|c|c|}
\hline \multirow{2}{*}{ Chemical sterilising agent } & \multicolumn{3}{|c|}{ Not exposed during pregnancy } & \multicolumn{3}{|c|}{ Exposed during pregnancy } \\
\hline & $\begin{array}{l}\text { Total No of } \\
\text { pregnancies }\end{array}$ & $\begin{array}{c}\text { Crude rate } \\
(\%)\end{array}$ & $\underset{(\%)}{\text { Adjusted rate }}$ & $\begin{array}{l}\text { Total No of } \\
\text { pregnancies }\end{array}$ & $\begin{array}{c}\text { Crude rate } \\
(\%)\end{array}$ & $\begin{array}{c}\text { Adjusted rate } \\
(\%)\end{array}$ \\
\hline $\begin{array}{l}\text { Ethylene oxide (with and without other agents) } \\
\text { Glutaraldehyde (with and without other agents) } \\
\text { Formaldehyde (with and without other agents) } \\
\text { Ethylene oxide (with glutaraldehyde) } \\
\text { Ethylene oxide alone } \\
\text { Glutaraldehyde alone }\end{array}$ & $\begin{array}{r}1004 \\
710 \\
1100 \\
704 \\
1068 \\
786\end{array}$ & $\begin{array}{r}9 \cdot 9 \\
7 \cdot 8 \\
11 \cdot 0 \\
7 \cdot 1 \\
10 \cdot 3 \\
8 \cdot 5\end{array}$ & $\begin{array}{l}7 \cdot 7 \\
7 \cdot 7 \\
8 \cdot 3 \\
6 \cdot 6 \\
7 \cdot 8 \\
7 \cdot 8\end{array}$ & $\begin{array}{r}146 \\
440 \\
50 \\
446 \\
82 \\
364\end{array}$ & $\begin{array}{l}19 \cdot 2^{* * *} \\
16 \cdot 4^{* * *} \\
12 \cdot 0 \\
17 \cdot 3^{* * *} \\
20 \cdot 7^{* *} \\
16 \cdot 5^{* * *}\end{array}$ & $\begin{array}{l}12 \cdot 7^{*} \\
9 \cdot 3 \\
8 \cdot 4 \\
11 \cdot 3^{*} \\
16 \cdot 1^{* *} \\
9 \cdot 4\end{array}$ \\
\hline
\end{tabular}

${ }^{*} \mathrm{p}<0.05,{ }^{* *} \mathrm{p}<0.01,{ }^{* * *} \mathrm{p}<0.001$

TABLE III-Details of spontaneous abortions among sterilising staff and nursing auxiliaries (controls) from 1973 to 1979. (Data obtained from hospital discharge register)

\begin{tabular}{|c|c|c|c|}
\hline & \multirow{2}{*}{$\begin{array}{l}\text { Total No of } \\
\text { pregnancies }\end{array}$} & \multicolumn{2}{|c|}{ Spontaneous abortions $(\%)$} \\
\hline & & Rate + & Ratio§ \\
\hline $\begin{array}{l}\text { Sterilising staff } \\
\text { Exposed to: } \\
\text { Ethylene oxide } \\
\text { Glutaraldehyde } \\
\text { Not exposed } \\
\text { Controls }\end{array}$ & $\begin{array}{r}253 \\
31 \\
178 \\
121 \\
368\end{array}$ & $\begin{array}{c}14 \cdot 2 \dagger \\
22 \cdot 6^{*} \\
12 \cdot 9 \\
9 \cdot 9 \\
9 \cdot 2\end{array}$ & $\begin{array}{l}19.3 \dagger \\
33.3^{*} \\
17.3 \\
12.6 \\
11.8\end{array}$ \\
\hline
\end{tabular}

${ }^{*} \mathbf{p}<0.05$ when compared with controls ( $\chi^{2}$ test)

$* p<0.05$ when compared
+ Not significant $(p<0 \cdot 1)$.

$\ddagger$ Number of spontaneous abortions/number of pregnancies.

$\$$ Number of spontaneous abortions/number of pregnan
$\S$ Number of spontaneous abortions/number of births.

\section{Discussion}

Studies based on questionnaires may be affected by recall and reporting bias, which occur particularly often in those of spontaneous abortions since individual recognition of early spontaneous abortions is likely to vary. ${ }^{15}$ Our study design for recording the obstetric history of sterilising staff could also introduce at least two kinds of asymmetry. Selection may take place during the occupational lifetime depending on reproductive health ${ }^{14}$; secondly, recent pregnancies; which are likely to be the exposed ones, may be recalled more accurately than previous ones, which were less likely to have been exposed to chemical agents. According to the figure all the groups of women reported a higher rate of spontaneous abortion in their most recent 
pregnancies. To eliminate the bias it was essential to adjust the data for the decade of the pregnancy recorded.

In our study three factors helped control the various types of bias. Firstly, the respondents were unlikely to be aware of the aim of our study since sterilising gases were not asked about; details of exposure were obtained from an independent source. Secondly, the comparison between the exposed and nonexposed pregnancies in the same women should reduce the effect of selection; the recognition of spontaneous abortions was presumably fairly uniform. Thirdly, two independent sources of data were used, questionnaires and the hospital discharge register.

Our findings cannot have resulted from the various biases for two reasons. Firstly, the results for formaldehyde did not correlate with those of ethylene oxide and glutaraldehyde; thus no uniform bias can explain the results. Secondly, the analysis of spontaneous abortions obtained from the hospital discharge register essentially confirmed the findings of the questionnaire. As the hospital data were independent of the answers to the questionnaire, they support the reliability of the results. We have used the hospital discharge register in several previous studies on spontaneous abortions. ${ }^{12-14}$

These results suggest that exposure to ethylene oxide in early pregnancy may increase the risk of spontaneous abortions. Glutaraldehyde may also not be absolutely safe, but it appears to be less potent. Ethylene oxide concentrations have been measured in many sterilising units in Finnish hospitals; eighthour weighted mean concentrations have ranged from 0.1 to 0.5 parts per million with peak concentrations up to 250 parts per million (measurements by Institute of Occupational Health). No measurements of glutaraldehyde concentrations are available but severe exposure can occur when open liquid baths are used. Exposure to formaldehyde in the sterilisation units may be minimal, particularly when gas chambers are used. The range of formaldehyde concentrations measured in sterilising units has been reported as 0.03-3.5 parts per million.

The present findings indicate that exposure to ethylene oxide in hospitals correlates with an increased frequency of spontaneous abortions. As studies of spontaneous abortions are inherently complex and difficult to control for, confirmation of the results is urgently needed so that the staff concerned in sterilising procedures can be protected.
We thank $\mathrm{Dr}$ W $\mathrm{F}$ Whimster for his linguistic advice and $\mathrm{Mr} \mathrm{P}$ Kyyrönen for some calculations.

\section{References}

1 Glaser ZR. Ethylene oxide: toxicology review and field study results of hospital use. $\mathcal{F}$ Environ Pathol Toxicol 1979;2:173-208.

${ }^{2}$ Fishbein L. Potential industrial carcinogens and mutagens. In: Studies in environmental science. Vol 4. Amsterdam: Elsevier, 1979.

${ }^{3}$ Miller JA, Miller EC. Ultimate chemical carcinogens as reactive mutagenic electrophiles. In: Hiatt $\mathrm{HH}$, Watson JD, Winsten JA, eds. Origins of human cancer. Cold Spring Harbor: Cold Spring Harbor Laboratory, 1977:605-27.

${ }^{4}$ Dunkelberg $\mathrm{H}$. On the oncogenic activity of ethylene oxide and propylene oxide in mice. Br $\mathcal{F}$ Cancer 1979;39:588-9.

5 Swenberg JA, Kerns WD, Mitchell RI, Gralla EJ, Pavkov KL. Induction of squamous cell carcinomas of the rat nasal cavity by inhalation exposure to formaldehyde vapor. Cancer Res 1980;40:3398-402.

${ }_{6}$ International Agency for Research on Cancer. Monographs on the evaluation of carcinogenic risk of chemicals to man. Vol 4. Lyons: International Agency for Research on Cancer, 1974.

${ }^{7}$ Hogstedt C, Rohlen O, Berndtsson BS, Axelson O, Ehrenberg L. A cohort study on mortality and cancer incidence among employees exposed to various chemicals in the production of ethylene oxide. $\mathrm{Br} \mathcal{F}$ Ind Med 1979;36:276-80.

${ }^{8}$ LaBorde JB, Kimmel CA. The teratogenicity of ethylene oxide administered intravenously to mice. Toxicol Appl Pharmacol 1980;56:16-22.

${ }^{9}$ Marks TA, Worthy WC, Staples RE. Influence of formaldehyde and Sonacide (potentiated acid glutaraldehyde) on embryo and fetal development in mice. Teratology 1980;22:512-8.

10 Breslow NE, Day NE. Statistical methods in cancer research. Vol 1. Lyons: International Agency for Research on Cancer, 1980.

${ }^{11}$ Hemminki K, Mutanen P, Saloniemi I, Luoma K. Congenital malformations and maternal occupation in Finland: multivariate analysis. $\mathcal{f}$ Epidemiol Commun Health 1981 ;35:5-10.

${ }^{12}$ Hemminki K, Niemi M-L, Saloniemi I, Vainio H, Hemminki E. Spontaneous abortions by occupation and social class in Finland. Int $\mathfrak{f}$ Epidemiol 1980;9:149-53.

${ }^{13}$ Hemminki K, Niemi M-L, Koskinen K, Vainio H. Spontaneous abortions among women employed in the metal industry in Finland. Int Arch Occup Environ Health 1980;47:53-60.

${ }^{14}$ Hemminki K, Niemi M-L, Kyyrönen P, Kilpikari I, Vainio H. Spontaneous abortions and reproductive selection mechanisms in rubber and leather industry in Finland. $\mathrm{Br} \mathcal{F}$ Ind $\mathrm{Med}$ (in press).

${ }^{15}$ Miller JF, Glue J, Williamson E, Gordon YB, Sykes A, Grudzinskas JG. Fetal loss after implantation. A prospective study. Lancet 1980;ii:554-6.

(Accepted 9 September 1982)
MOUSE-EAR is a low herb, creeping upon the ground by small strings, like the Strawberry plant, whereby it shoots forth small roots, whereat grow, upon the ground, many small and somewhat short leaves, set in a round form together, and very hairy, which, being broken, do give a whitish milk. From among these leaves spring up two or three small hoary stalks about a span high, with a few smaller leaves thereon; at the tops whereof stands usually but one flower, consisting of many pale yellow leaves, broad at the point, and a little dented in, set in three or four rows (the greater uppermost) very like a Dandelion flower, and a little reddish underneath about the edges, especially if it grow in a dry ground; which after they have stood long in flower do turn into down, which with the seed is carried away with the wind.

It grows on ditch banks, and sometimes in ditches, if they be dry, and in sandy grounds. It flowers about June or July, and abides green all the Winter. The Moon owns this herb also; and though authors cry out upon Alchymists, for attempting to fix quicksilver by this herb and Moonwort, a Roman would not have judged a thing by the success; if it be to be fixed at all, it is by lunar influence. The juice thereof taken in wine, or the decoction thereof drank, doth help the jaundice, although of long continuance, to drink thereof morning and evening, and abstain from other drink two or three hours after. It is a special remedy against the stone, and the tormenting pains thereof: as also other tortures and griping pains of the bowels. The decoction thereof with Succory and Centaury is held very effectual to help the dropsy, and them that are inclining thereunto, and the diseases of the spleen. It stays the fluxes of blood, either at the mouth or nose, and inward bleeding also, for it is a singular wound herb for wounds both inward and outward: It helps the bloody flux, and helps the abundance of women's courses. There is a syrup made of the juice hereof and sugar, by the apothecaries of Italy, and other places, which is of much account with them, to be given to those that are troubled with the cough or phthisic. The same also is singularly good for ruptures or burstings. The green herb bruised and presently bound to any cut or wound, doth quickly solder the lips thereof. And the juice, decoction, or powder of the dried herb is most singular to stay the malignity of spreading and fretting cankers and ulcers whatsoever, yea in the mouth and secret parts. The distilled water of the plant is available in all the diseases aforesaid, and to wash outward wounds and sores, by applying tents of cloths wet therein. (Nicholas Culpeper (1616-54) The Complete Herbal, 1850.)

MEDICINES APPROPRIATED TO THE MOUTH AND NOSE-Apply no stinking medicine to a disease in the nose, for such offend not only the nose, but also the brain; neither administer medicines of any ill taste to a disease in the mouth, for that subverts the stomach, because the tunicle of the mouth and of the stomach is the same: and because both mouth and nostrils are ways by which the brain is cleansed, therefore are they infected with such vices as need almost continual cleansing, and let the medicines you apply to them be either pleasant, or at least, not ingrateful, (Nicholas Culpeper (1616-54) The Complete Herbal, 1850.) 